\title{
Evaluating final-year medical students' communication skills using an observational rating scale in Shiraz medical school.
}

\author{
Sahar Bahraminia ${ }^{1}$, Mitra Amini ${ }^{2 *}$ \\ ${ }^{1}$ Shiraz Medical School, Shiraz University of Medical Sciences, Shiraz, Iran \\ ${ }^{2}$ Clinical Education Research Center, Shiraz University of Medical Sciences, Shiraz, Iran
}

\begin{abstract}
Background: The way doctors communicate with their patients has basic effects on patient outcomes. The aim of this study was to use a rating scale based on Calgary-Cambridge guide for evaluating doctor and patient communication skills

Methods: This was a cross-sectional performance-based assessment study, done during 2016-2017 in Shiraz Medical School. This project was performed on 125 last year medical students (Interns). An observational rating scale was used based on Calgary-Cambridge guide to medical interview. The validity and reliability of the rating scale was determined in our previous study. The researcher observed the interns' behavior and scored the scale based on the performance of each intern. The scores of each item in the rating scale were from 1 (very weak) to 5 (excellent).

Results: Of the 128 interns who were included in the study, $81(63 \%)$ were women and $47(37 \%)$ were men. The general communication skill score between doctors and patients in this study was 3.18 out of 5 . The level of communication skills of the female interns was higher than the male interns. This difference was statistically significant $(\mathbf{P}<0001)$. The highest average communication skill between the doctor and the patient was in the ward with low crowding. This difference was statistically significant $(\mathbf{P}<0001)$.

Discussion: The mean communication skills score in this study showed that communication skills training was insufficient and should be emphasized more. Medical students' preparation in communication skills must put emphasis on identifying opportunities to advance communication skills that improve their future patient experience. It is necessary to have emphasis on communication skills training in the core curriculum.
\end{abstract}

Keywords: Communication skills, Medical students.

Accepted on July 16, 2018

\section{Introduction}

A number of recent developments in medical education have emphasized the importance of communication skills [1]. Communication is very important in medical care. The way doctors communicate with their patients has basic effects on patient outcomes [2-5].

Clinical communication is defined as any communication between health care providers and patients using verbal and non-verbal skills [6]. Medical students need to be able to take a patient's history well and to share information and describe procedures and treatment ways. Communication is important not only for professional patient interaction but also within the healthcare team. Effective communication leads to good working relationships and increased patient satisfaction [7].

A randomized controlled trial showed that influence of doctor and patients' communication can reduce participants' anxiety and negative feelings [8]. Effective communication will also increase patients' understanding of treatment, enhance compliance and lead to improved health.

Many studies have also shown that doctors with good interpersonal abilities will diagnose patients' problems earlier [9]. Most complaints against doctors stem from problems in communication [10]. Indeed, considering the rise in patients' rights and expectations, medical students need to learn communication skills more effectively [11].

Some researchers have found that communication skills can depend on the doctor or patient's sex; female doctors communicate with higher degrees of empathy than male doctors $[12,13]$. There are several studies on communication skills between doctors and patients using self-assessment questionnaires $[14,15]$.

The aim of this study was to use a rating scale based on Calgary-Cambridge guide for evaluating doctor and patient communication skills [16]. 


\section{Method}

\section{Study design}

This was a cross-sectional performance-based assessment study, done during 2016-2017 in Shiraz Medical School, southern Iran. Data were collected in 6 months.

\section{Study population}

This project was performed on 125 interns (medical intern is a term used in some countries such as Iran to describe a physician in the last year of training that does not yet have a full license to practice medicine unsupervised). The total population of medical interns was 200 . These interns were oncall in different clinical wards at hospitals affiliated to Shiraz University of Medical Sciences.

\section{Sample size}

Sample size was determined based on a statistical formula to be 125 interns, using mean average with a $5 \%$ error. The interns were selected using stratified random sampling.

\section{Data gathering tool}

In this research, an observational rating scale was used based on Calgary-Cambridge guide to medical interview [16]. In fact, the principles of the questionnaire (Calgary-Cambridge guide) were maintained, but a number of changes were also made. The validity and reliability of the rating scale was determined in our previous study [17]. This rating scale is designed to assess complete communication efficacy of the whole physician-patient encounter, summarizing the quality of the interaction from the initiation to termination of interview.

The rating scale consists of five parts:

1. Individual profile of the intern that includes; gender, population and type of hospital ward (paediatric ward, Ob-Gyn ward, surgery ward, internal ward, and other wards).

2. A number of questions in the questionnaire are related to the points that were important at the beginning of the interview (Does he/she introduce him/her and ask the patient's name?).

3. A group of questions related to the skills that were important in continuing the interview.

4. Some questions about how to take history and physical examination.

5. There were also some questions about the important issues at the end of the interview.

The interns were selected randomly based on their clinical rotations. In order to increase the accuracy of investigating communication skills, the researcher personally attended the ward and observed the interns' behavior and scored the scale based on the performance of each intern. The scores of each item in the rating scale were from 1 (very weak) to 5 (excellent).

\section{Ethical aspects and data analysis}

To consider ethical issues, the interns were justified about the purpose of the study before being observed, but the rating scale and its contents were confidential.

\section{Data analysis}

Data were collected and analyzed using SPSS software. Kolmogorov smirnov test was used for checking normality of data that was not significant and showed data had normal distribution. For measuring the difference in communication skills based on gender and visiting wards Student's t-test and analysis of variances was used. $\mathrm{P}<0.05$ was considered significant.

\section{Results}

Of the 128 interns who were included in the study, $81(63 \%)$ were women and $47(37 \%)$ were men. $24(18 \%)$ interns were in the Ob-Gyn ward, 25 (20\%) in the pediatric ward, $25(20 \%)$ in the internal medicine ward, $26(21 \%)$ in the surgery ward, and $28(22 \%)$ in the other ward were examined.

Table 1. Mean and standard deviation of interns' scores.

\begin{tabular}{lll}
\hline Interview Item & Domain & Mean $\mathbf{~ S D ~ ( f r o m ~ 5 ) ~}$ \\
\hline Acceptable appearance of interns & \\
\hline Saying hello to the patient & 3.56 \\
\hline Introducing himself/herself to the patient & Interview initiation \\
\hline Asking patients' name and calling the patient by name & Interview initiation \\
\hline Explaining the purpose of the interview by simple words & Interview initiation \\
\hline Friendly interaction with patients & Interview initiation \\
\hline Non-verbal communication with patients & 3.54 & Interview conduction \\
\hline
\end{tabular}




\begin{tabular}{lll}
\hline Showing empathy with patients & Interview conduction & 3.08 \\
\hline Encouraging the patient to talk more & Interview conduction & 3.48 \\
\hline Listening to the patient words & Interview conduction & 2.95 \\
\hline Responding properly to the patients' questions without any judgment about them & Interview conduction & 3.64 \\
\hline Ask open questions & History/physical examination & 3.03 \\
\hline Ask detail of symptoms & History/physical examination & 3.71 \\
\hline Use appropriate questions and explanation especially in sensitive issues & History/physical examination & 3.03 \\
\hline Do correct physical examination & History/physical examination & 3.67 \\
\hline Asking questions about what has not be discussed & Interview termination & 3.29 \\
\hline Responding extra questions of the patients & Interview termination & 2.61 \\
\hline Summing up the results of the interview properly & Interview termination & 2.59 \\
\hline Informing the end of the interview & Interview termination & 2.72 \\
\hline
\end{tabular}

The results of each part of the rating scale are shown in Table 1 based on mean and standard deviation of each item of the rating scale. As shown, in the interview initiation the best mean score was in the item "Acceptable appearance of interns" and the worse mean was related to the item "Introducing himself/ herself to the patient".

In the item of interview conduction the best score was in the item "Respond properly to patient questions without any judgment about the patient" and the worst score was in the items "Non-verbal communication with patients" and "listening to the patients" words".

In history and physical examination in all items the mean score was above 3 out of 5 . In the termination of interview, the best score was in the item "Asking questions about what was not discussed" and the worst scores were in the item "Summing up the results of the interview properly". The general communication skill score between doctors and patients in this study was 3.18 .

The mean score of all items in communication skills between the doctor and the patient were 3.3 in women and 2.9 in men, which indicated that the level of communication skills of the female medical interns was higher than the male medical interns. This difference was statistically significant using student's t-test $(\mathrm{P}<0001)$.

Communication skills between physicians and patients based on population congestion showed that in different wards, with a low traffic crowding, the average mean was 3.81 , with a moderate traffic crowding average of 3.18 , and with a high overcrowding, the average communication skill was 2.9. In this way, the highest average communication skill between the doctor and the patient was in the ward with low crowding. This difference was statistically significant using ANOVA analysis $(\mathrm{P}<0001)$.

The average physician and patient communication skills mean in the Ob-Gyn ward was 3.1, in the pediatric ward were 3.24, in the internal medicine ward were 3.23 , in the surgery ward were 3.27 , and were 3.04 in the other wards. ANOVA analysis showed no significant relationship between the types of wards and the communication skills scores between the doctor and patient.

\section{Discussion}

Physicians' communication skills have a significant influence on patient well-being and associate with enhanced healthcare outcomes [9]. In the present study communication skills of final-year students were assessed using a valid and reliable rating scale during their clerkship in a real setting.

The mean communication skills score in this study showed that communication skills training was insufficient and should be emphasized more. Other studies have reported similar results in Iran and other countries indicating insufficiency in the training of doctors about communication skills $[18,19]$.

In the interview initiation the appearance of interns was acceptable but the result of introducing to patients was not satisfactory. The important purpose of doctor-patient communication is to improve the patients' outcome. Perfect interviews with patients require following a series of connected guidelines for patients' encounters and ability to interview with paying attention at the initiation stage to age, group, temper, and personal characteristics of different patients. It is necessary to have a plan, from the first second of each encounter up to the end [20,21].

In the area of interview conduction in the item of responding to patients' questions without judgment about the patient, the interns' score was acceptable and in the items of non-verbal communication skills and listening to patients words, it was not acceptable. This finding was similar to our previous study [17].

Silverman et al. reported that one of the challenges regarding the physician's non-verbal communication skills in the modern world is computers. They recommended that physicians should look at their patients instead of looking at their computers [22]. Currently, non-verbal communication is highly important in the 
medical interview. Physicians need to recognize patients' nonverbal communication and also need to be conscious of their own non-verbal message. Physicians' use of eye contact, body posture, movement and facial expression will affect the success of the consultation [22].

In the area of history taking and performing a perfect physical examination, the results were acceptable in all items. One study showed that those students that have education about communication skills have better clinical skills [23].

In the area of interview termination, the best results were seen in the item of asking questions about what has not been discussed and the worst scores was in the item summing up the interview. This result may be due to shortage of time, a large number of patients that are being visited by one intern and lack of acceptable education.

Boyle et al. introduced a model for communication skills teaching to medical students as invite, listen, and summarize. This model emphasized on building rapport, gathering worthy data, and improving compliance of patients by summarizing the interview at the end of it [24].

There were significant differences between men and women with regard to their performance in communication skills. Female interns obtained higher scores. Female doctors have a tendency to communicate with higher degrees of empathy in empathic conditions produced by patients [13].

Another important factor in communication skills score in the present study was ward crowding. Crowding leads to less time to devote to each patient, less time for communicating and counselling with patients, besides physicians become exhausted and cannot concentrate on patients' problems [25].

There was no significant difference between the interns' communication skills scores in different wards. This result was different form the result of a study by Baig et al. reported the need for a content specific checklist for assessing communication skills [26].

In recent years there has been a noticeable growth of research on communication skills in medicine. Research evidence has emphasized the significance of this essential skill and revealed that effective physician-patient communication must be taught, learned, and longitudinally reviewed during the curriculum [27].

Research on communication skills is one of the medical research priorities in the Eastern Mediterranean region and Iran [28]. Integrating medical education and healthcare delivery system in Iran provide a unique opportunity for medical students to learn communication skills in real practice in teaching hospitals and communities [29]. The core communication skills should be taught to all medical students; however, there is a chance to have some electives in special and advanced communication skills course for gifted and talented students [30].

The strength of the present study is that the study is a real performance assessment study and preparing tools for performance assessment like rating scale and observing the interns' behavior is a difficult task. One of the limitations of this study is that findings may be inadequate with respect to generalization since data were obtained from one medical school in south of Iran. Another limitation is that observation may suffer from biases such as observer bias by the researcher and Hawthorne effect by the participants. Although these limitations exist, we believe that this study will deliver an example of methods of performance assessment for clinical communication skills and is useful for people planning new assessment methods in this field. It may also motivate conversation amongst experts, since there are still numerous unanswered questions, many of which will indorse research chances for all concerned. The results of this study yield to designing a course in the medical students' core curriculum about communication skills in the first year of medical school. This course will be continued as a longitudinal theme across the 7 year medical curriculum in Shiraz medical school.

\section{Conclusion}

Teachers in the arena of clinical communication skills may discover it valuable to assess students' communication skills performance using rating scales. This method enables them to give feedback to their students on the specific deficits observed. Medical students' preparation in communication skills must put emphasis on identifying opportunities to advance communication skills that improve their future patient experience. Considering education of this important topic in the core curriculum is necessary.

\section{Acknowledgement}

This study was obtained from a thesis for obtaining medical degree that was done by the first author (Sahar Bahramnia) with proposal number 10991 that was approved by Deputy of Research of Shiraz University of Medical Sciences. The authors thank all the students who participated in this study.

\section{References}

1. Rider EA, Hinrichs MM, Lown BA. A model for communication skills assessment across the undergraduate curriculum. Med Teach 2006; 28: 127-134.

2. Bensing JM, Verheul W. The silent healer: the role of communication in placebo effects. Patient Educ Couns 2010; 80: 293-299.

3. Di Blasi Z, Harkness E, Ernst E, Georgiou A, Kleijnen J. Influence of context effects on health outcomes: a systematic review. Lancet 2001; 357: 757-762.

4. Brody H, Miller FG. Lessons from recent research about the placebo effect-from art to science. J Amer Med Assoc 2011; 306: 2612-2613.

5. Griffin SJ, Kinmonth AL, Veltman MW, Gillard S, Grant J, Stewart M. Effect on health-related outcomes of interventions to alter the interaction between patients and practitioners: a systematic review of trials. Ann Fam Med 2004; 2: 595-608. 
6. Von Fragstein M, Silverman J, Cushing A. UK consensus statement on the content of communication curricula in undergraduate medical education. Med Educ 2008; 42: 1100-1107.

7. Laidlaw A, Hart J. Communication skills: An essential component of medical curricula. Part 1: Assessment of clinical communication: AMEE Guide No. 51. Med Teach 2011; 33: 6-8.

8. Osch MV, Dulmen SV, Vliet LV, Bensing J. Specifying the effects of physician's communication on patients' outcomes: A randomized controlled trial. Patient Educ Couns 2017; 100: 1482-1489.

9. Parker SM, Clayton JM, Hancock K. A systematic review of prognostic/end-of-life communication with adults in the advanced stages of life-limiting illness: patient/ caregiver preferences for the content, style, and timing of information. J Pain Symptom Manage 2007; 1: 81-93.

10. Halperin E. Grievances against physicians: 11 years' experience of a medical society grievance committee. West J Med 2000; 173: 235-238.

11. Van der Zeijden A. The patient rights movement in Europe. Pharmaco Economics 2000; 18: 7-13.

12. Dielissen $\mathrm{P}$, Bottema $\mathrm{B}$, Verdonk $\mathrm{P}$, Lagro-Janssen $\mathrm{T}$. Attention to gender in communication skills assessment instruments in medical education: a review. Med Educ 2011; 45: 239-248.

13. Bylund CL, Makoul G. Empathic communication and gender in the physician-patient encounter. Patient Educ Couns 2002; 48: 207-216.

14. Symons AB, Swanson A, McGuigan D, Orrange S, Akl EA. A tool for self-assessment of communication skills and professionalism in residents. BMC Med Educ 2009; 9: 1 .

15. Hudelson P, Perron NJ, Perneger T. Self-assessment of intercultural communication skills: a survey of physicians and medical students in Geneva, Switzerland. BMC Med Educ 2011; 11: 63.

16. Kurtz S, Silverman J. The Calgary-Cambridge Referenced Observation Guides: an aid to defining the curriculum and organizing the teaching in communication training programmes. Med Educ 1996; 30: 83-89.

17. Amini M, Yousefi S, Moghadami M. Using a checklist to access communication skills in last year medical students. J Med Educ 2008; 1: 3-9.

18. Singh V, Khandelwal R, Bohra S, Gupta R, Gupta BS Evaluation of communication skills of physicians about asthma. J Assoc Physicians India 2002; 50: 1266-1269.

19. Tavakol M, Torabi S, Lyne OD, Zeinaloo AA. A quantitative survey of intern's knowledge of communication skills: an Iranian exploration. BMC Med Educ 2005; 5: 6.

20. Greco M, Spike N, Powell R, Brownlea A. Assessing communication skills of GP registrars: a comparison of patient and GP examiner ratings. Med Educ 2002; 36: 366-376.

21. Chan CS, Wun YT, Cheung A, Dikinson JA, Chan KW. Communication skills of general practitioners; any room for improvement? How much can it be improved? Med Educ 2003; 37: 514-526.

22. Silverman J Kinnersley P. Doctors' non-verbal behaviour in consultations: look at the patient before you look at the computer. Br J Gen Pract 2010; 60: 76-78.

23. Managheb SE, Zamani A, Shams B, Farajzadegan Z. The effect of communication skills training by video feedback method on clinical skills of interns of Isfahan University of medical sciences compared to didactic methods. Health Educ J 2012; 71: 564-552.

24. Boyle D, Dwinnell B, Platt F. Invite, listen, and summarize: a patient-centered communication technique. Acad Med 2005; 80: 29-32.

25. Shayne P, Lin M, Ufberg JW, Ankel F, Barringer K, Morgan-Edwards S. The effect of emergency department crowding on education: blessing or curse? Acad Emerg Med 2009; 16: 76-82.

26. Baig LA, Violato C, Crutcher RA. Assessing clinical communication skills in physicians: Is the skills context specific or generalizable? BMC Med Educ 2009; 9: 22.

27. Kurtz S, Silverman J, Draper J. Teaching and learning communication skills in medicine (3rd ed). Radcliffe Publishing Ltd, Abingdon, Oxon 2013.

28. Amini M, Kojuri J, Lotfi F, Karimian Z, Abadi ASH. Research priorities in medical education in the Eastern Mediterranean Region. Eastern Mediterranian Health J 2012; 18: 687-692.

29. Salehi A, Harris N, Lotfi F, Hashemi N, Kojuri J, Amini M. Reform in medical and health sciences educational system: a Delphi study of faculty members' views at Shiraz University of Medical Sciences. Eastern Mediterranian Health J 2014; 20: 151-161.

30. Amini M, Kojuri J, Karimian Z, Lotfi F, Moghadami M, Dehghani MR. Talents for future: Report of the second national medical science Olympiad in Islamic republic of Iran. Iran Red Crescent Med J 2011; 13: 377-381.

\section{*Correspondence to}

Mitra Amini

Clinical Education Research Center

Shiraz University of Medical Sciences

Shiraz

Iran 